Acta Theriologica 41 (4): 383-394, 1996.

PL ISSN 0001-7051

\title{
Effect of supplemental food on a cyclic Clethrionomys glareolus population at peak density
}

\author{
Ola LÖFGREN*, Birger HÖRNFELDT and Ulf EKLUND
}

Löfgren O., Hörnfeldt B. and Eklund U. 1996. Effect of supplemental food on a cyclic Clethrionomys glareolus population at peak density. Acta Theriologica 41: 383-394.

The impact of supplemental food on a cyclic bank vole Clethrionomys glareolus (Schreber, 1780) population was studied at peak density. We provided high energy food (sunflower seeds) to a 3.15 ha live-trapping grid and used a 5.06 ha unfed grid as a control. Density of adult females and immatures increased 3-fold in response to the extra food. In contrast, density of adult males did not change significantly. The rise in density of adult females, but not of adult males, altered the functional sex ratio. Loss rate of fed adults remained the same as for controls, whereas immature loss rate was reduced by the extra food. Dispersal of immatures from the control into the food supplemented grid was higher than the reverse. Growth and body mass of fed immatures were lower than of controls. Reduced dispersal and increased immigration of immatures both contributed significantly to the overall rise in density when food was added.

Department of Animal Ecology, Umeå University, S-901 87 Umeå, Sweden

Key words: Clethrionomys glareolus, voles, food supplementation, density, body mass

\section{Introduction}

The importance of food in causing vole population cycles is still under intensive debate (cf Andersson and Jonasson 1986, Batzli 1988, Hansson and Henttonen 1988, Hörnfeldt 1994, Löfgren 1995c). Attempts to alter the food supply of voles have given contradictory results as to the possible role of food as a trigger of vole population cycles (Boutin 1990). However, food addition experiments generally revealed a 2-3 fold rise in density (Andrzejewski 1975, Bujalska 1975, Gilbert and Krebs 1981, Desy and Batzli 1989, Saitoh 1989). In contrast, extra food did not prevent population declines in numbers and the major population dynamics was not altered (Gilbert and Krebs 1981, Taitt and Krebs 1981, 1983, Desy and Thompson 1983, Ford and Pitelka 1984, Henttonen et al. 1987). Supplemental feeding often extended the breeding season (Watts 1970, Andrzejewski 1975, Cole and Batzli 1978, Taitt and Krebs 1981, 1983, Ford and Pitelka 1984, Saitoh 1989), but see for example Gilbert and Krebs (1981). Maturation rate of young may

*Present adress: Department of Environmental Planning and Design, Luleå University, S-971 87 Luleå, Sweden 
increase and age at first reproduction may be reduced by extra food, but there is no general consistency among different experiments (cf Boutin 1990). A part of the rise in vole density upon food addition has been assigned to increased immigration (Gilbert and Krebs 1981, Young and Stout 1986). However, it is rarely known whether the voles actually moved from the surroundings into the food supplemented grids (but see Saitoh 1989).

Positive effects on growth and body mass upon supplemental feeding were reported for Microtus spp. by Cole and Batzli (1979), Desy and Thompson (1983), Taitt and Krebs (1983), Desy and Batzli (1989) and for Clethrionomys spp. by eg Andrzejewski (1975) and Banach (1986). However, some laboratory experiments indicated that gut size and hence body mass may be reduced if easily digestible foods are provided (Gross et al. 1985, Hansson 1985, Hansson and Jaarola 1989).

Vole population fluctuations are cyclic in northern Sweden (eg Hörnfeldt et al. 1986, Hörnfeldt 1994). Here we studied the effects of supplementary feeding with high energy food on a population of Clethrionomys glareolus (Schreber, 1780) at peak density. We mainly aimed to study the effects on density and individual movements, but we also considered any effects on body mass, reproductive activity and population structure.

\section{Materials and methods}

\section{Study area}

We used two vole trapping grids in a coniferous forest near Hällnäs $\left(64^{\circ} 19^{\prime} \mathrm{N}, 19^{\circ} 29^{\prime} \mathrm{E}\right)$ in northern Sweden. Picea abies and Pinus sylvestris were predominating trees. The field layer was mainly scattered stands of Vaccinium myrtillus or Deschampsia flexuosa. Vaccinium vitis-idaea, Empetrum nigrum, and Calluna vulgaris were locally abundant at dry localities. The ground cover was predominantly bryophytes. Ericson (1977) gave a detailed description of the study site vegetation.

Vole trapping and food manipulation

In summer-autumn 1984, voles were simultaneously censused in two adjacent live-trapping grids (30 m apart) at 2-3 week intervals. This year the $C$. glareolus population had a cyclic density peak in autumn (Fig. 1; see also Hörnfeldt 1994). The present control grid was used in a long term vole trapping programme in 1980-1984 (Löfgren 1989, 1995a, b). During the food supplementation period each trapping session (2-3 days) comprised 6-9 complete trap checks at 6-12 h intervals (morning, noon and evening). One multiple capture live-trap (Ugglan special) was used at each station. Trap stations were spaced in a regular $15 \times 15 \mathrm{~m}$ pattern in the control, and in a $30 \times 30 \mathrm{~m}$ pattern in the food supplemented grid (Fig. 2). The control comprised 256 trap stations covering 5.06 ha, and the supplemented grid comprised 48 trap stations covering 3.15 ha (estimates without boundary strip).

Traps were baited with rolled oats. Within the food supplemented grid we obtained a higher frequency of multiple captures. Thus, to avoid short-term food shortage during captivity more bait was provided in the traps on the supplemented grid than in control grid traps. Supplemental feeding with sunflower seeds started at end of the mid-August trapping session and continued throughout two trapping sessions in early and late September (Fig. 1). On the food supplemented grid seeds were provided at each trap station $(n=48)$ from automatic feeders. The feeders were 5-1 plastic cans mounted upside down in a stage of wood (Fig. 2). Seeds taken by the voles were automatically replaced by new ones. The feeders were checked and refilled regularly to obtain a constant ad libitum 


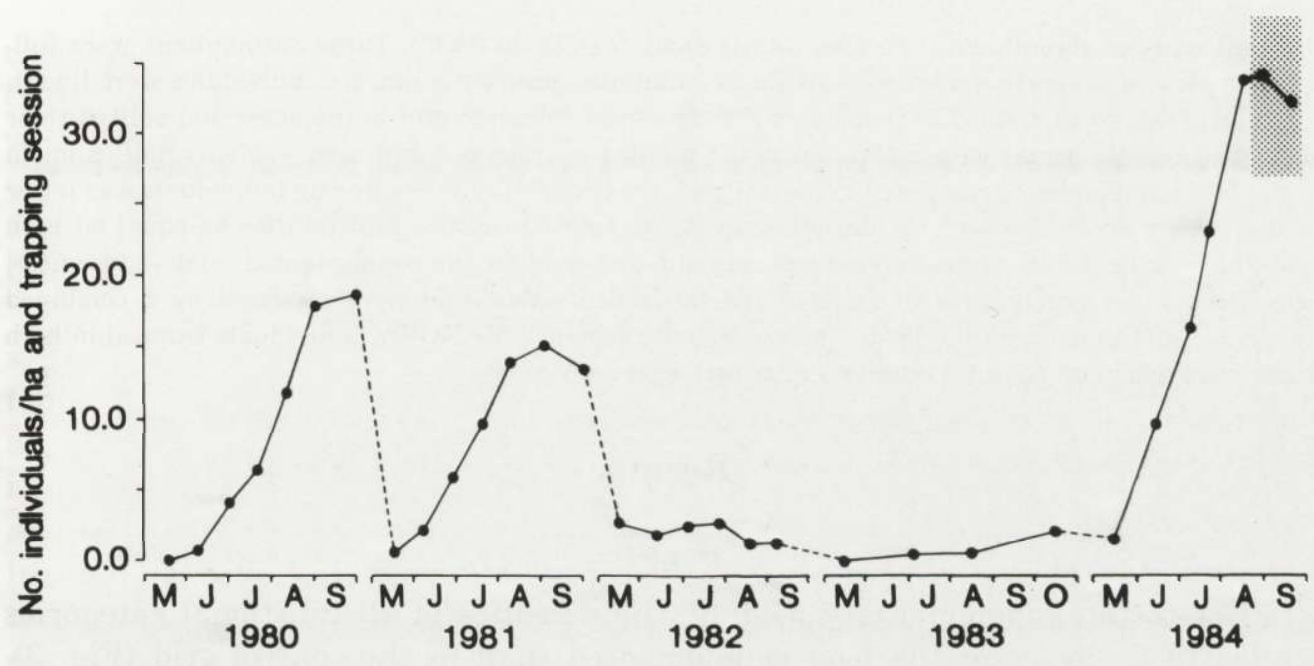

Fig. 1. Actual population density of Clethrionomys glareolus on control grid in 1980-1984. The time period for the experiment with supplemental food is indicated (shaded area).

food supply; $50-75 \%$ of the sunflower seeds disappeared from the feeders between consecutive trapping periods.

Voles captured were individually marked by toe-clipping and subsequently checked for: species, individual number, sex, body mass (to nearest $0.5 \mathrm{~g}$ ), reproductive status, and age. Age was determined by fur examination according to Viro (1979). Functional categories were defined from age and reproductive status according to Myllymäki (1977a, b): immatures refer to both juveniles $(<1$ month old, rapidly growing individuals) and subadults ( $>1$ month old, grown up voles). Adults refer to both reproductive and post-reproductive individuals.

To get comparable density estimates for each trapping session on both grids, we used the Schumacher and Eschmeyer Method and calculated densities (number per hectare) with 95\% confidence limits (Krebs 1989). A prerequisite for this method is that the population can be regarded as

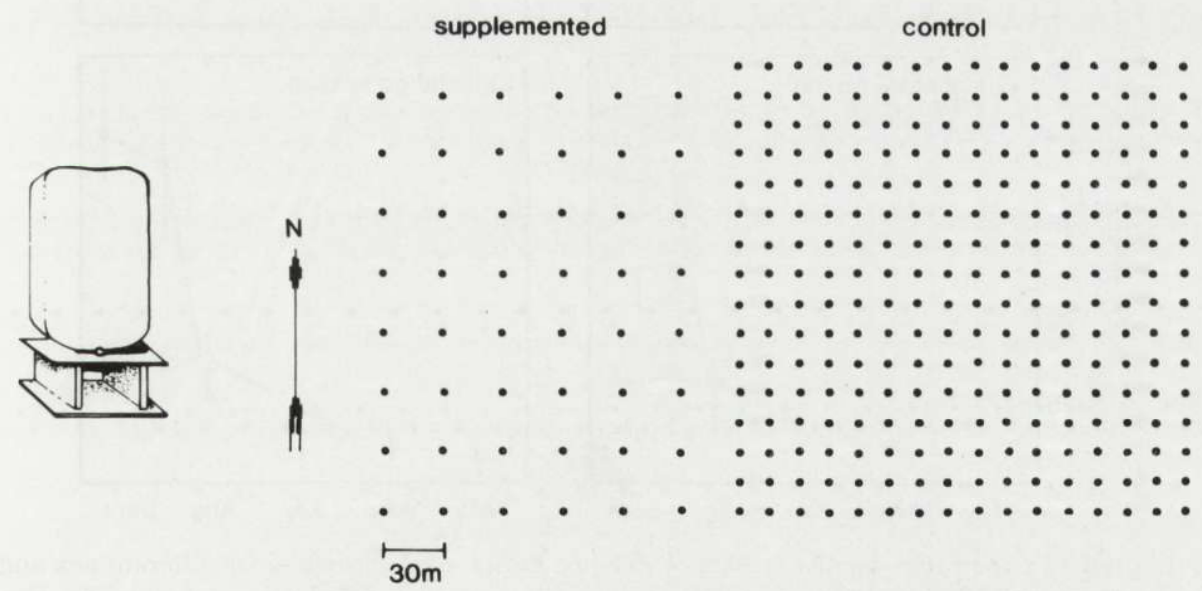

Fig. 2. Distribution of trap stations (dots) on food supplemented and control grids. One automatic feeder (illustrated) with sun flower seeds was placed at each trap station on the experimental grid. 
constant without recruitment or losses during sampling (Krebs 1989). These assumptions were fullfilled as plots of proportion marked individuals on number previously marked individuals were linear.

Individuals were defined as dispersers if they moved from one grid to the other and shifted their geometric activity center with $\geq 45 \mathrm{~m}$. Since the number of traps per unit area was only half as much in the food supplemented compared to control grid, the probability for capturing individuals was lower in the former area. However, in statistical tests, we treated capture probabilities as equal on both grids, so we most likely overestimated loss rate and dispersal for the supplemented relative to control grid. Body mass and growth of resident individuals in either grid were analysed by a combined univariate and multivariate repeated measurements designed MANOVA. Individuals trapped in both areas were excluded from the analysis of growth and body mass.

\section{Results}

\section{Density}

Prior to the supplementary feeding, the densities of all functional categories tended to be lower in the food supplemented than in the control grid (Fig. 3). However, after feeding was initiated, density of adult females as well as of immatures of both sexes increased 3 -fold in the fed area, whereas it remained
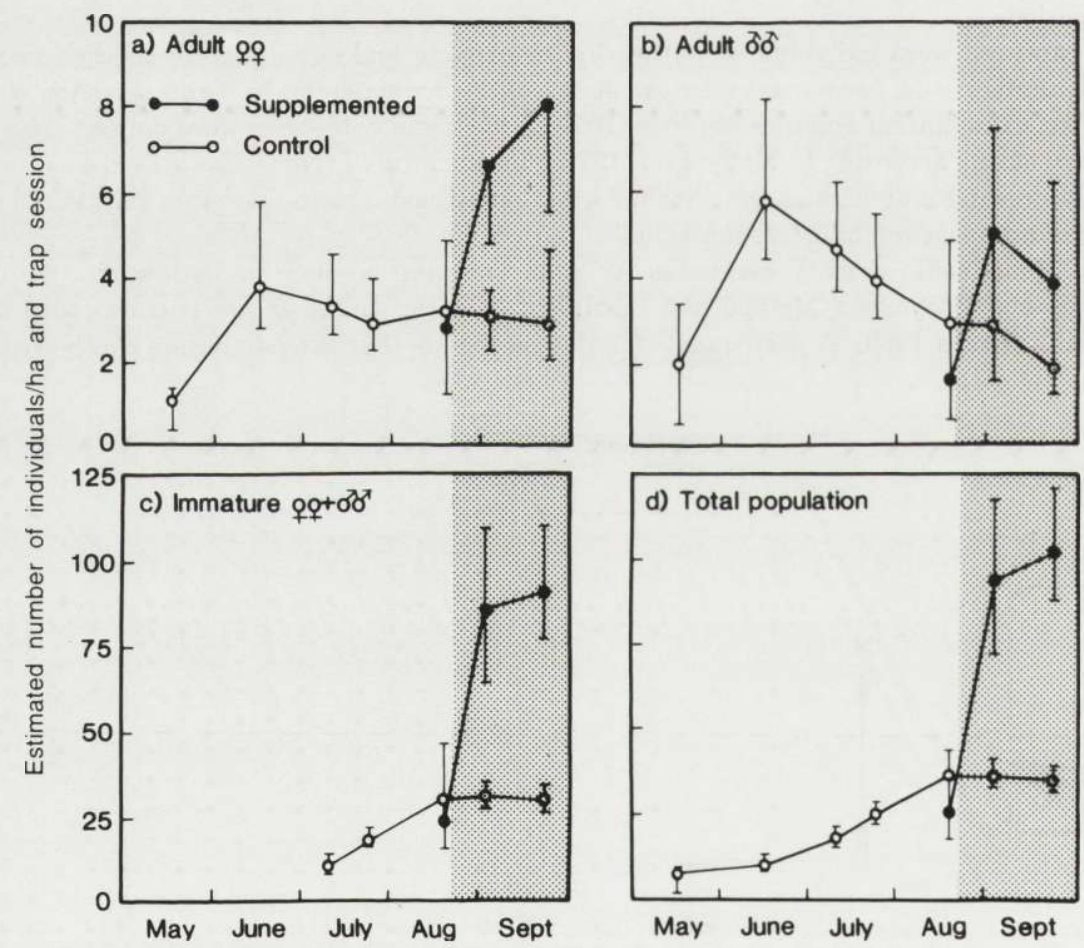

Fig. 3. Estimated population density ( $\pm 95 \%$ confidence limits) of $C$. glareolus for different sex and age classes $(a-c)$ as well as for all voles together (d) on food supplemented and control grids. Feeding started at end of the mid-August trapping session and lasted throughout the September sessions (shaded area). 
unchanged in the control area (Fig. 3a, c). The lack of density increase in the control represented the normal seasonal pattern at this time of the year, coinciding with cessation of reproduction (Fig. 1; see also Löfgren 1989). In contrast to other categories, density of adult males did not change significantly in the fed compared to unfed area (Fig. 3b). In autumn total density was about three times higher in the fed than unfed area (Fig. 3d).

In the control, the density of adult females was fairly constant throughout the season with 3-4 females per ha. This represented the saturation level of territorial females in the control area that was achieved well before the start of the food supplementation period (Fig. 3a and Löfgren 1995a). With extra food, density increased from 3 to 7 females per ha (Fig. 3a). This rise was entirely caused by an increase in the number of breeding yearlings (most likely immigrants; see below). The density of overwintered females declined in both areas throughout the autumn. In contrast to females, male breeding yearlings did not increase due to extra feeding.

\section{Loss rates and dispersal}

The loss rate of immatures was higher on the control than on the food supplemented grid, and there were no differences between the sexes (Fig. 4a, b). A Mantel-Haenszel $\chi^{2}$-test including all immatures (sexes pooled) marked in mid-August and early September and subsequently followed to late September revealed a significant difference in loss rate between the grids $\left(\chi^{2}=7.1, p=0.008\right)$.

a Immature $\$ 9$

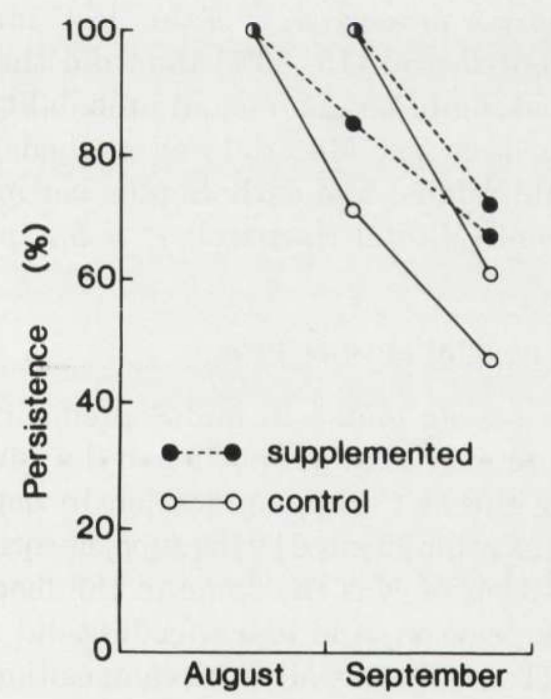

b Immature $0^{\circ} \sigma^{\circ}$

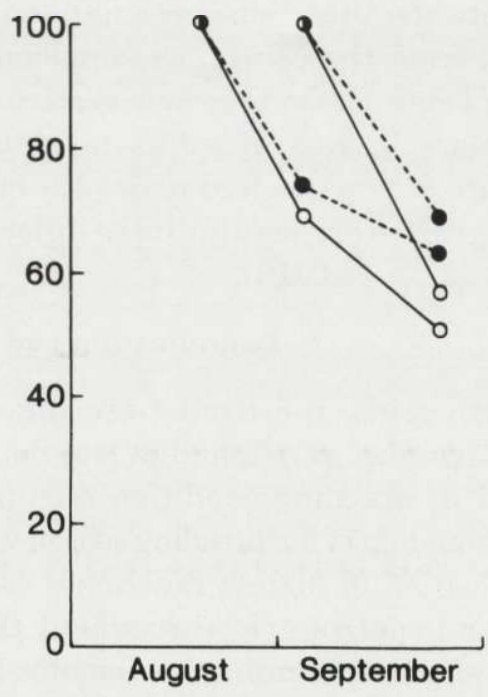

Fig. 4. Persistence of immature females (a) and males (b) of C. glareolus on supplemental food and control grids. Feeding started at end of the mid-August trapping session and lasted throughout the September sessions. Inital number of individuals as in Table 1. 
Table 1. Initial numbers, loss rates and dispersal of immature C. glareolus on control (C) and experimental (E) grids. Total losses refer to all individuals marked in mid-August or early September that had disappeared at end of experiment. Dispersal refers to the fraction of the total losses assigned to movements between grids.

\begin{tabular}{|c|c|c|c|c|c|c|}
\hline & \multicolumn{2}{|c|}{ Initial number } & \multicolumn{2}{|c|}{ Total losses (\%) } & \multicolumn{2}{|c|}{ Dispersal (\%) } \\
\hline & $\mathrm{C}$ & $\mathrm{E}$ & $\mathrm{C}$ & $\mathrm{E}$ & $\mathrm{C}$ to $\mathrm{E}$ & $\mathrm{E}$ to $\mathrm{C}$ \\
\hline \multicolumn{7}{|c|}{ Mid-August markings } \\
\hline Females & 51 & 33 & 53 & 33 & 15 & 0 \\
\hline Males & 75 & 27 & 49 & 37 & 30 & 10 \\
\hline \multicolumn{7}{|c|}{ Early September markings } \\
\hline Females & 23 & 64 & 39 & 28 & 22 & 6 \\
\hline Males & 28 & 85 & 43 & 31 & 17 & 0 \\
\hline
\end{tabular}

In contrast, the loss rate of adults of any sex did not differ between the food supplemented and control grid.

No adults moved between the grids after the supplemental feeding was initiated. In addition, the immature losses due to dispersal from one grid to the other were also small. Among the immatures (both sexes), 19 out of 177 (11\%) marked individuals moved from the control into the supplemented grid. The corresponding figures for the supplemented grid were 2 out of 209 (1\%). Thus, the large density increase on the food manipulated grid was not caused by a drainage of individuals from the control grid. Although the number of individuals that moved between the grids was small, a larger proportion of of the "lost" immatures dispersed from the control to supplemented grid (15-30\%) than did the reverse (0-10\%) (Table 1). On the conservative assumption of an equal probability for lost individuals to be recaptured in the other area (see Material and methods), overall movements of females and males (in mid-August and early September markings) between grids were significantly different (Mantel-Haenszel: $\chi^{2}=5.2, p=0.022$ and $\chi^{2}=5.5, p=0.019$ ).

\section{Reproduction and population structure}

On both grids, the female breeding season ended in mid-September, and no pregnant females were found in late September. A minor portion of the adult males were still in breeding condition during the last trapping session in both areas. Thus, termination of the breeding season was not influenced by the supplemental feeding.

Composition of female functional categories was the same in the food supplemented and control grid throughout the season, and extra feeding did not alter the ratio of adult to immature females (Table 2). Initially, the composition of male functional categories did not differ significantly between grids, but feeding temporarily altered the ratio of adult to subadult males and a significant difference was apparent in early September (Table 2). The difference was mainly caused by 
Table 2. Composition of female and male functional categories and sex ratios (females : males) for trapped voles on control (C) and experimental (E) grids. Supplemental feeding started at end of the mid-August trapping session. The significance of difference in composition of functional categories is according to $\chi^{2}$-tests.

\begin{tabular}{|c|c|c|c|c|c|c|}
\hline & \multicolumn{2}{|c|}{ Mid-August } & \multicolumn{2}{|c|}{ Early September } & \multicolumn{2}{|c|}{ Late September } \\
\hline & $\mathrm{C}$ & $\mathrm{E}$ & $\mathrm{C}$ & $\mathrm{E}$ & $\mathrm{C}$ & $\mathrm{E}$ \\
\hline \multicolumn{7}{|l|}{ Females } \\
\hline Adults \% & 19.5 & 22.9 & 17.5 & 16.8 & 17.3 & 19.0 \\
\hline Subadults \% & 79.2 & 71.4 & 77.5 & 76.8 & 69.1 & 74.6 \\
\hline Juveniles \% & 1.3 & 5.7 & 5.0 & 6.4 & 13.6 & 6.4 \\
\hline Total numbers & 77 & 35 & 80 & 95 & 81 & 126 \\
\hline Difference in composition & \multicolumn{2}{|c|}{ ns } & \multicolumn{2}{|c|}{ ns } & \multicolumn{2}{|c|}{ ns } \\
\hline \multicolumn{7}{|l|}{ Males } \\
\hline Adults \% & 15.8 & 8.1 & 15.1 & 4.7 & 9.9 & 4.6 \\
\hline Subadults \% & 78.9 & 86.5 & 79.8 & 92.5 & 83.5 & 88.6 \\
\hline Juveniles \% & 5.3 & 5.4 & 5.1 & 2.8 & 6.6 & 6.8 \\
\hline Total numbers & 95 & 37 & 99 & 107 & 91 & 132 \\
\hline Difference in composition & \multicolumn{2}{|c|}{ ns } & \multicolumn{2}{|c|}{$p<0.05$} & \multicolumn{2}{|c|}{ ns } \\
\hline Adult sex ratio & 1.00 & 2.67 & 0.93 & 3.20 & 1.56 & 4.00 \\
\hline Subadult sex ratio & 0.81 & 0.78 & 0.78 & 0.74 & 0.74 & 0.80 \\
\hline
\end{tabular}

the rise in number of immature males but not of adult males on the supplemented grid (Fig. 3b, c and Table 2).

Due to the unequal rise in density of adult females and males in the food manipulated area, more adult females per male were trapped within the supplemented grid than in control grid (Table 2). On the control grid, the adult sex ratio never deviated significantly from unity. Before feeding was initiated the sex ratio on the supplemented grid was also even $\left(\chi^{2}=2.2, p>0.1\right)$. However, the sex ratio became female biased on the supplemented grid both in early and late September $\left(\chi^{2}=5.8, \chi^{2}=10.8, \mathrm{df}=1, p<0.02, p<0.01\right.$, respectively). Thus, supplementary feeding biased the adult functional sex ratio towards females. The sex ratio of subadults did not not differ between the grids (Table 2).

The ratio of year-born to overwintered breeders was also analysed, but no significant differences between the fed and unfed grids were found. On neither grid did the immatures first trapped in mid-August or early September attain maturity later in autumn.

\section{Individual growth and body mass}

In contrast to other field experiments, our supplementary fed immatures grew slower and weighed less than unfed ones. The difference was most apparent among immatures persistent from mid-August to late September. Among these individuals there was no between grid difference in body mass before feeding in 


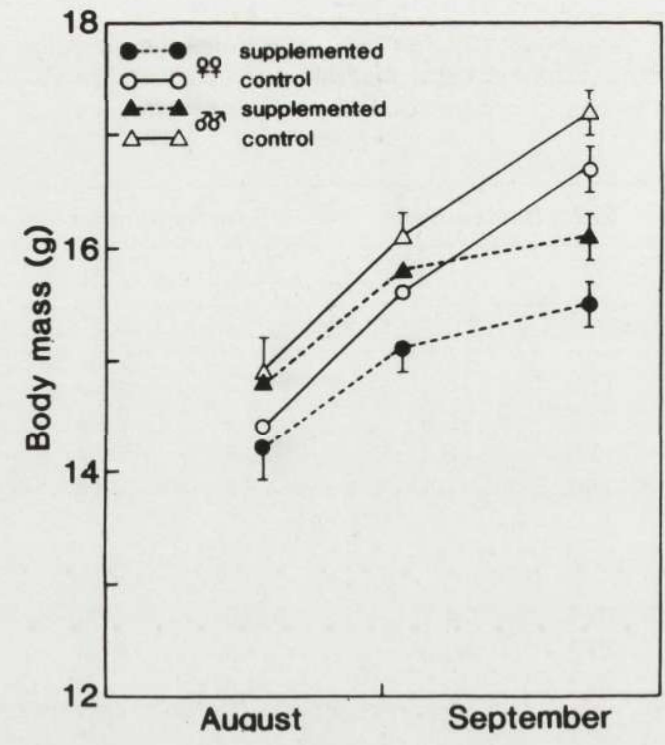

Fig. 5. Development of body mass (mean \pm 1 SE) of immatures on supplemental food and control grids. Data refer to the same individuals that were persistent on one grid only from mid-August to end of the experiment.

mid-August (oneway ANOVA, sexes pooled, $p>0.2$ ), but by the end of the food manipulation period the difference was obvious (Fig. 5). Analysis of variance (repeated measurements designed MANOVA) of body mass of these individuals revealed differences between the grids, both for growth $\left(F_{2,214}=6.0, p=0.003\right)$, and for body mass $\left(F_{1,107}=8.1, p=0.005\right)$. No differences related to sex, or the combination of sex and treatment, were found.

Growth of immatures marked in early September was similar to those marked in mid-August. Fed individuals tended to be smaller than unfed ones also after this short period. In contrast to the immatures, growth and body mass of the adults did not differ between grids.

\section{Discussion}

\section{Density and population structure}

Despite the occurrence in our C. glareolus population of a cyclic density peak (Fig. 1), which in fact was the next most highest peak in the 1970's and 1980's (cf Hörnfeldt 1994), supplementary feeding caused a 3-fold density increase. Indeed, the rise in density in our study was of similar magnitude to many other food addition experiments (cf Gilbert and Krebs 1981, Boutin 1990). In that sense we consider our study to be an important but unreplicated repetition of these other, also mostly unreplicated, food addition studies (for a similar reasoning, see Hargrove and Pickering 1992). We find that these experiments together stress the importance of food limitation in vole populations, in the present case, clearly, also in a cyclic C. glareolus population (see also Hansson 1979, Hörnfeldt et al. 1986). In contrast, the feeding experiment of Henttonen et al. (1987) only marginally 
affected density of cyclic voles in northern Finland. However, they manipulated declining populations, used food of lower quality (oats), and fed the voles less intensely than we did.

Breeding Clethrionomys spp. females are territorial, but improved food conditions may reduce home range size and also promote spatial overlap among individuals (Bujalska 1975, Andrzejewski and Mazurkiewicz 1976, Ims 1987a). Such changes probably promoted the present rise in density of adult females on the supplemented grid. In contrast to breeding females, C. glareolus immatures of both sexes are non-territorial, and they have overlapping activity areas (eg Bujalska 1970, Bujalska and Grüm 1989). Therefore immatures should not have been socially restricted to increase their numbers, and indeed this category caused the main rise in overall density.

In contrast to other categories, adult males did not increase in density as a response to the extra food. Evidence suggests that food is the key resource for reproductive females, whereas availability of mates is most important to reproductive males (eg Ostfeldt 1985 1990, Ims 1987b). However, despite the fact that density of adult females was three times as high in the fed as unfed area, density of adult males did not rise and the functional sex ratio became extremely female biased. Thus, if mates were the critical resource for males, the number of males should - but did not - increase in response to the increased female density. Other studies in the control area also revealed that densities of reproductive males were the same irrespective of female density ( $O$. Löfgren, unpubl.). This suggests that a male does not monopolize a certain number of females, but rather cover a specific area independently of female density.

\section{Loss rates, dispersal and immigration}

Improved 'survival' in response to extra feeding has been frequently reported, but the distinction between mortality, emigration and immigration has rarely been clear (cf Boutin 1990, but see Saitoh 1989). In the present study losses of immatures were $10-20 \%$ higher from the unfed than fed grid. A large portion of this difference apparently was explained by a higher dispersal rate of immatures from the unfed to fed grid than the reverse. In fact, the difference in dispersal rates between the grids was of the same magnitude as the difference in loss rates. Hence, reduced dispersal on the food grid was partly responsible for the density increase there. Improved survival in situ may also have contributed to the lower loss rate on the fed than unfed grid. However, this was probably of minor importance, since differences in dispersal seemed to explain most of the differences in loss rates between the grids. The larger dispersal from the control to the food supplemented grid than the reverse also indicated that immigration was large to the supplemented grid, especially as dispersers were likely to enter that grid from a much larger surrounding area than the control. This conclusion is also in line with the study of Babińska-Werka (1990) who found that both immigration and emigration of $C$. glareolus occured rapidly as a response to supplementation and later to withdrawal of 
extra food in a Polish forest. Loss rate and dispersal of adults were unaffected by the extra food. This result is in line with other studies on Clethrionomys voles, and it suggests a high degree of residency among individuals already settled as breeders (eg Bondrup-Nielsen 1984, Gliwicz 1990, 1992, Löfgren 1995a).

\section{Reproduction}

The rise in density of fed adult females and immatures in the present study was not explained by a prolonged breeding season, nor was the rise in density linked to a higher maturation rate of young voles in situ. However, as feeding started near the end of the reproductive season, such effects were less likely to be obtained. However, Gilbert and Krebs (1981) initiated supplementary feeding of $C$. rutilus with sunflower seeds already in spring, but they also failed to extend the breeding season. Thus, experiments aimed to manipulate the breeding season should address the critical question: Are the foods used adequate to support reproduction? If triggers are neccessary, as observed by Berger et al. (1977) and Negus and Berger (1977), and if the supplemented food does not contain them, then the extra food should not be expected to alter the breeding period.

\section{Growth and body mass}

Individuals should use increased available energy from extra food for reproduction and/or body growth. However, in the present study the maturation rate of immatures was unaffected, and their growth and body mass were reduced in the presence of the extra food. This latter result contrasts to other feeding experiments, where body mass increased or was unaffected (cf Boutin 1990).

Since traps on the fed grid were provided with more food (see Material and methods), short-term food shortage on the fed grid during captivity just prior to weighing seemed unlikely as a cause of the observed mass difference. In contrast, the increasing difference in body mass throughout the study period, suggested a different long term change in body mass of the immatures on fed and unfed grids.

In a study similar to ours, Gilbert and Krebs (1981) found no effect on individual growth and body mass when they supplemented $C$. rutilus voles with sunflower seeds (high energy), while juvenile growth increased when oats (low energy) was provided. Interestingly, in an 18 day laboratory experiment, Gross et al. (1985) found that the size of the nutritive tract (and hence body mass) of $M$. ochrogaster decreased with increased food quality (digestability). Similar results were reported by Hansson (1985) and Hansson and Jaarola (1989) for C. glareolus and M. agrestis. Alternatively, the much higher densities and increased social contacts on the supplemented grid compared to the control grid in it itself, may have influenced the growth rate of the individuals. Such mechanisms are known to occur among microtine rodents (cf Batzli et al. 1977). Thus, from these findings we would in fact expect a reduced body mass of the immatures that were given high energy sunflower seeds.

Acknowledgements: We thank all colleagues and students who supported us during this study. Especially we like to thank J.-E. Mattiasson, J. Nygren and K.-E. Renhorn for assistance during field work. G. Andersson, G. Borgström and M.-L. Löfgren gave technical assistance and G. Marklund drew 
the figures. Comments by R. A. Ims, C. Otto, G. Englund and anonymous referees improved the manuscript a lot. Financial support was received from Helge Ax:son Johnsons stiftelse, Hierta-Retzius stipendiefond, J. C. Kempes minnesfond, Stiftelsen Seth M. Kempes Minne and Olle och Signhild Engkvists Stiftelser.

\section{References}

Andersson M. and Jonasson S. 1986. Rodent cycles in relation to food resources on an alpine heath. Oikos 46: 93-106.

Andrzejewski R. 1975. Supplementary food and the winter dynamics of bank vole populations. Acta Theriologica 20: 23-40.

Andrzejewski R. and Mazurkiewicz M. 1976. Abundance of food supply and size of the bank voles home range. Acta Theriologica 21: 237-253.

Babińska-Werka J. 1990. Response of bank voles to a new source of food and its withdrawal. Acta Theriologica 35: 191-199.

Banach K. 1986. The effect of increased food supply on the body growth rate and survival of bank voles in an island population. Acta Theriologica 31: 45-54.

Batzli G. O. 1988. The role of nutrition and carrying capacity in models of small rodent population dynamics. Oikos 52: 224-226.

Batzli G. O., Getz L. L. and Hurley S. S. 1977. Suppression of growth and reproduction of microtine rodents by social factors. Journal of Mammalogy 58: 583-591.

Berger P. J., Sanders E. H., Gardner P. D. and Negus N. C. 1977. Phenolic plant compounds functioning as reproductive inhibitors in Microtus montanus. Science 195: 575-577.

Bondrup-Nielsen S. 1984. The role of habitat heterogeneity and female spacing behaviour in density regulation of Clethrionomys gapperi. Ph D thesis, University of Alberta, Edmonton, Alberta, Canada: 1-180.

Boutin S. 1990. Food supplementation experiments with terrestrial vertebrates: patterns, problems, and the future. Canadian Journal of Zoology 68: 203-220.

Bujalska G. 1970. Reproduction stabilizing elements in an island population of Clethrionomys glareolus. Acta Theriologica 15: 381-412.

Bujalska G. 1975. The effect of supplementary food on some parameters in an island population of Clethrionomys glareolus (Schreber, 1780). Bulletin de L'Academie Polonaise des Sciences 23: 23-27.

Bujalska G. and Grüm L. 1989. Social organization of the bank vole (Clethrionomys glareolus, Schreber 1780) and its demographic consequences: a model. Oecologia 80: 70-81.

Cole R. F. and Batzli G. O. 1978. Influence of supplemental feeding on a vole population. Journal of Mammalogy 59: 809-819.

Cole R. F. and Batzli G. O. 1979. Nutrition and population dynamics of the prairie vole, Microtus ochrogaster, in central Illinois. Journal of Animal Ecology 48: 455-470.

Desy E. A. and Batzli G. O. 1989. Effect of food availability and predation on prairie vole demography: a field experiment. Ecology 70: 411-421.

Desy E. A. and Thompson C. F. 1983. Effects of supplemental food on a Microtus pennsylvanicus population in central Illinois. Journal of Animal Ecology 52: 127-140.

Ericson L. 1977. The influence of voles and lemmings on the vegetation in a coniferous forest during a 4-year period in northern Sweden. Wahlenbergia 4: 1-114.

Ford G. R. and Pitelka F. A. 1984. Resource limitation in populations of the california vole. Ecology 65: $122-136$.

Gilbert B. S. and Krebs C. J. 1981. Effects of extra food on Peromyscus and Clethrionomys populations in the southern Yukon. Oecologia 51: 326-331.

Gliwicz J. 1990. The first born, their dispersal, and vole cycles. Oecologia 83: 519-522.

Gliwicz J. 1992. Patterns of dispersal in non-cyclic populations of small rodents. [In: Animal dispersal, small mammals as a model. N. C. Stenseth and W. Z. Lidicker, Jr, eds]. Chapman \& Hall, London: 147-159. 
Gross J. E., Wang Z. and Wunder B. A. 1985. Effects of food quality and energy needs: changes in gut morphology and capacity of Microtus ochrogaster. Journal of Mammalogy 66: 661-667.

Hansson L. 1979. Food as a limiting factor for small rodent numbers: Tests of two hypotheses. Oecologia 37: 297-314.

Hansson L. 1985. Geographic differences in bank voles Clethrionomys glareolus in relation to ecogeographical rules and possible demographic and nutritive strategies. Annales Zoologici Fennici 22: 319-328.

Hansson L. and Henttonen H. 1988. Rodent dynamics as community processes. TREE 3: 195-200.

Hansson L. and Jaarola M. 1989. Body size related to cyclicity in microtines: dominance behaviour or digestive efficiency? Oikos 55: 356-364.

Hargrove W. W. and Pickering J. 1992. Pseudoreplication: a sine qua non for regional ecology. Landscape Ecology 6: 251-258.

Henttonen H., Oksanen T., Jortikka A. and Haukisalmi V. 1987. How much do weasels shape microtine cycles in the northern Fennoscandian taiga? Oikos 50: 353-365.

Hörnfeldt B. 1994. Delayed density dependence as a determinant of vole cycles. Ecology 75: 791-806.

Hörnfeldt B., Löfgren O. and Carlsson B.-G. 1986. Cycles in voles and small game in relation to variations in plant production indices in Northern Sweden. Oecologia 68: 496-502.

Ims R. A. 1987a. Responses in spatial organisation and behaviour to manipulations of the food resource in the vole Clethrionomys rufocanus. Journal of Animal Ecology 56: 585-596.

Ims R. A. $1987 \mathrm{~b}$. Male spacing system in microtine rodents. American Naturalist 130: 475-484.

Krebs C. J. 1989. Ecological methodology. Harper \& Row, New York: 1-654.

Löfgren O. 1989. Do intrinsic or extrinsic factors limit reproduction in cyclic populations of Clethrionomys glareolus and C. rufocanus? Holarctic Ecology 12: 54-59.

Löfgren O. 1995a. Spatial organization of cyclic Clethrionomys females: occupancy of all available space at peak densities? Oikos 72: 29-35.

Löfgren O. 1995b. Niche expansion and increased maturation rate of Clethrionomys glareolus in the absence of competitors. Journal of Mammalogy 76: 1100-1112.

Löfgren O. 1995c. Interactions between social factors and resources in the population dynamics of cyclic voles. $\mathrm{Ph} \mathrm{D}$ thesis, Umeå university, Umeå: 1-87.

Myllymäki A. 1977a. Demographic mechanisms in the fluctuating populations of the field vole Microtus agrestis. Oikos 29: 468-493.

Myllymäki A. $1977 \mathrm{~b}$. Intraspecific competition and home range dynamics in the field vole Microtus agrestis. Oikos 29: 553-569.

Negus N. C. and Berger P. J. 1977. Experimental triggering of reproduction in a natural population of Microtus montanus. Science 196: 1230-1231.

Ostfeldt R. S. 1985. Limiting resources and territoriality in microtine rodents. American Naturalist 126: 1-15.

Ostfeldt R. S. 1990. The ecology of territoriality in small mammals. TREE 5: 411-415.

Saitoh T. 1989. Effects of added food on some attributes of an enclosed vole population. Journal of Mammalogy 70: 772-782.

Taitt M. J. and Krebs C. J. 1981. The effect of extra food on small rodent populations. II. Voles Microtus townsendii. Journal of Animal Ecology 50: 125-137.

Taitt M. J. and Krebs C. J. 1983. Predation, cover, and food manipulations during a spring decline of Microtus townsendii. Journal of Animal Ecology 52: 837-848.

Watts C. H. S. 1970. Effect of supplementary food on breeding woodland rodents. Journal of Mammalogy 51: 169-171.

Viro P. 1979. Moulting and the structure of the fur in the bank vole, Clethrionomys glareolus (Schreber 1780), in the vicinity of Oulu, Finland. Aquilo, Seria Zoologica 19: 49-58.

Young B. L. and Stout J. S. 1986. Effects of extra food on small rodents in a south temperate zone habitat: demographic responses. Canadian Journal of Zoology 64: 1211-1217.

Received 16 April 1996, accepted 5 October 1996. 